\title{
Theoretical justification for development as an institution for the development of investment and construction
}

\author{
Elena Soboleva ${ }^{1, *}$ \\ ${ }^{1}$ Moscow State University of Civil Engineering, Yaroslavskoye shosse, 26, Moscow, 129337, Russia
}

\begin{abstract}
The article is devoted to the theoretical aspects of development, project activities, the search and substantiation of the institutional importance of the development of this direction in the current economic situation in Russia, the construction industry, the problems of realizing development projects and the impact of the quality of operational evaluation of development projects on overall efficiency, efficiency and development of construction activities in a crisis and the quality of project management. An algorithm for the formation of development activity as an institution for the development of the investment and construction sphere in Russia has been developed. Theoretically, the algorithm and methodological approach to the quality management of the development project efficiency is justified.
\end{abstract}

\section{Introduction}

This industry accumulates not only significant financial and investment flows, but also provides employment for the population in serving and related industries. Construction can and should be an industry where innovative technologies are actively developing. This applies to the process of building civil and industrial facilities, and to the production of building materials, and to the issues of building management. The construction industry reflects the state of the investment attractiveness of the country and is a reflection of the entire Russian economy: through the building complex, all investments are made - both to industry and to other spheres. This industry connects and interacts with all sectors, with any investment projects. Here is a very active competitive environment. At the same time, construction refers to those industries that are the driving force of the economy and direct it forward [1].

The main goal of the development project is to extract income from the increment of the value of real estate. In order to achieve this main objective, the development project must satisfy the following conditions, which, in the aggregate of their performance, ensure the achievement of economic efficiency:

1. to ensure the return of resources invested in the project;

2. provide income for the resources involved in the project;

3. Ensure maximum profitability [2].

\footnotetext{
*Corresponding author: alenas_06@mail.ru
} 
Development can be characterized as a way of organizing investment and construction activities in the entire range of existing modifications and depending on the breadth of coverage of the life cycle of the property.

Construction and development refers to industry segments that are not sustainable to the crisis, as they combine the sale of investment products with high debt burden. At the beginning of the crisis, the lack of liquidity in the money market had a very negative impact on the development of the real estate sector, thereby determining the negative trends of the crisis period [3]:

1. shortage of funds for the development of development projects;

2. reduction in business activity and effective demand;

3. slowing down the commissioning of real estate and freezing of construction projects;

4. difficulties with servicing loans and growing debt load of developers;

5. an increase in the number of lawsuits, the transfer of assets to creditors on account of debt repayment.

\section{Experimental part}

Today, the problems of the current situation in the Russian development market are proposed to be divided into external and internal problems of implementation and management of development projects.

External problems of the Russian development market:

1. small experience in development activities;

2. many companies engaged in real estate development, call themselves investment, construction investment, and sometimes management companies, ie there is no common understanding of identification differences;

3. real estate development market is very blurred: many companies combine the development activities of construction, investment and / or consultancy activities;

4. imperfection of the legislation with regard to the institution of property: development activity is generally not regulated by law;

5. imperfection of the credit and investment system: excessive length with approval of necessary documentation for the development project;

6. the overall situation in the country's economy is not yet stable. [4]

Internal problems of Russian development:

1. the contradiction of goals, methods and forms of activity;

2. the incorrectness of long-term planning, and often its absence;

3. opacity of the price of administrative resources;

4. priority of administrative methods for solving problem situations;

5. uneconomical and ineffective management: low level of staff skills and lack of motivation;

6. illiterate accounting and control: substandard budgeting of the development project; or lack thereof;

7. legal vulnerability;

8. use of outdated methods of team interaction;

9. manipulation of consumer ambitions;

10. the incorrectness of the methods used to evaluate the performance of the developer.

The main objectives of the development of development activities in the Russian

Federation in a modern market economy:

1. protection of the rights of shareholders / owners;

2. differentiation of rights and responsibilities of the participants of the development project;

3. increase of contractual discipline; 
4. strategic orientation of the activities of management and the project team;

5. development of analytical, evaluation and legal areas of development;

6. development and introduction of forms of economic incentives for employees involved in the development project;

7. the creation of adequate financial technologies for the formalization, planning, accounting and control of the activities of development companies;

8. development of professional communication management of the development project;

9. professional development of personnel with the focus of universality of professionalism of top management of developer companies;

10. introduction of logistic models for accuracy and controllability of the implementation of the tasks of project feasibility:

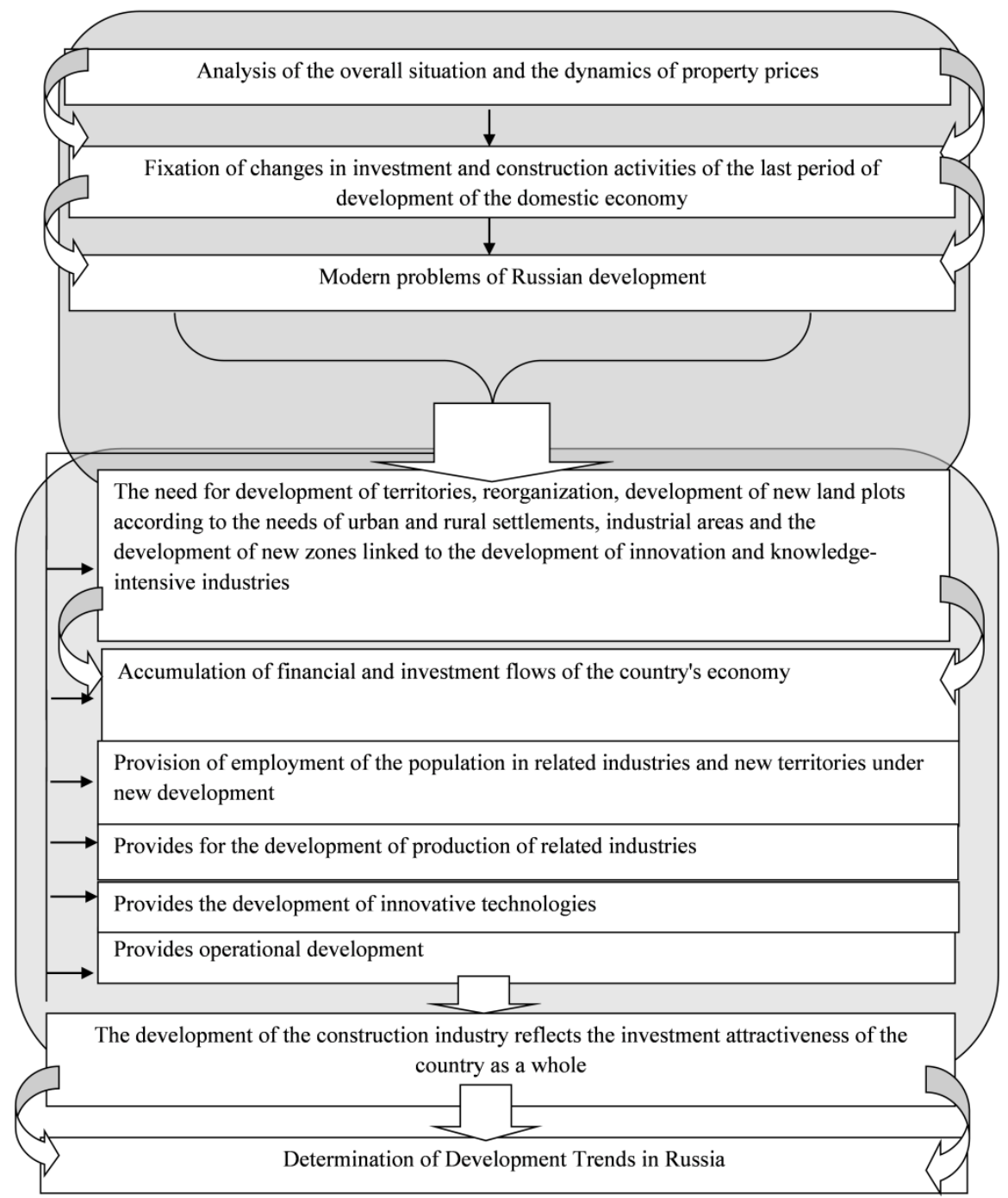

Fig. 1. Algorithm for the formation of development activities as an institution for the development of investment and construction in Russia [5].

11. development and introduction of accounting and control technologies in the form of models of financial and economic orientation with the interrelation of the marketing 
component and engineering surveys taking into account the innovations of scientific and technical developments;

12. ensuring investment attractiveness and social significance;

13. ensuring the positioning of the need to develop development activities;

14. development of adequate methods for assessing the effectiveness and management of development projects.

During the formation and accumulation of the presented tasks of development activity, an algorithm for the formation of development activity as an institution for the development of the investment and construction sphere in Russia (Fig.1).

\section{Results}

At present, it is necessary to pay attention to important trends in the development and study of development: the importance and relevance of the scientific approach to development; definition of development standards and development of a methodology for the organization of development; the creation of a methodology to assess and improve the quality of management of development activities; development of a set of methods for monitoring and managing the effectiveness of development projects [6]. The developer project can be represented in the form of a functional structure (Figure 2).

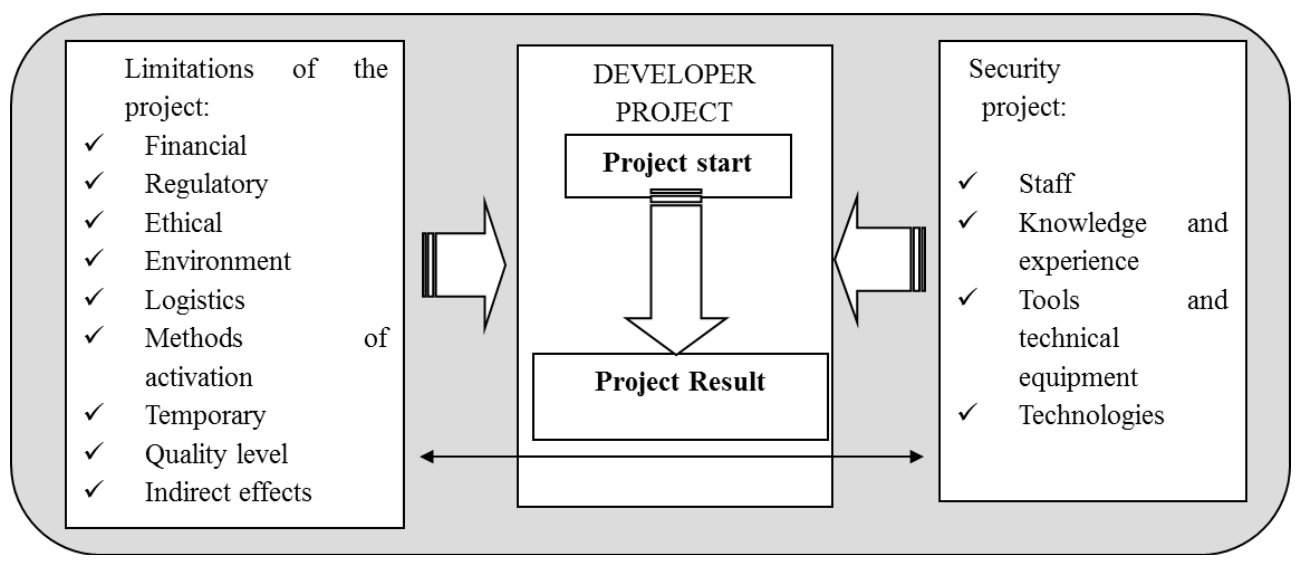

Fig. 2. Functional structure of the development project.

Thus, the quality of management of the development project is an indicator of the effectiveness of the project as a whole, i.e. the fulfillment of the conditions for a clear interrelation of these components within the development project and the execution of the corresponding functional will lead to the expected result of the developer. The development project is an independent formation that undergoes qualitative development during the life cycle of the passage of all stages of development: from conception to physical realization and realization with obtaining the maximally planned profit and integrated effectiveness of a given mission. As a result of the correct management of the development project, the profit increases, the profitability of investor-developer investments increases due to the speed of project implementation and professional management of not only costs, but also revenues through monitoring of the sale price market. The key to the success of the project, i.e. fulfillment of the set goals, is a careful study of the development strategy of a particular real estate object [7].

\section{Conclusion}


The result of the development project is the emergence of a new real estate object that meets the specific needs of business and the population and its characteristics, such as materiality, durability, high capital intensity; which, when implemented, will allow the developer to achieve the final goal of the project - making a profit [7].

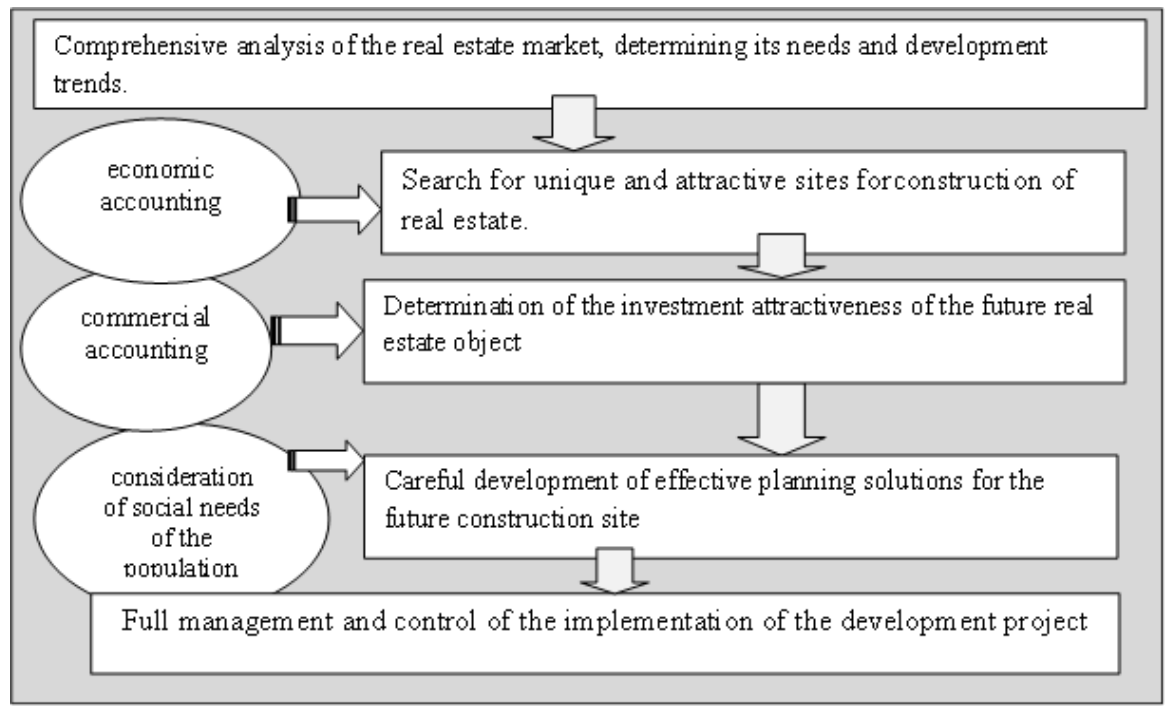

Fig. 3. Structure of strategic planning of the development project.

Therefore, the strategy of the development project, as a long-term implementation object, should be formed in accordance with the methodological principles of modern strategic management, which consists in building a strategy through forecasting, calculation, monitoring and analysis. Strategic planning should be aimed at solving the issue of the final aspiration of the development project in its functioning; and at what level the developer will need to go out to achieve goals not simply by survival, but with mandatory development. And development in the present case must be steadily effective to achieve as a result of the planned profit.

\section{References}

1. C. Delmastro, E. Lavagno, L.Schranz, Tunnelling and Underground Space Technology 55, 103-111 (2016)

2. F. Aggogeri, A. Borboni, R. Faglia, A. Merlo, S. De Cristofaro, Applied Mechanics and Materials, 336-338 (2013) DOI: 10.4028/ www.scientific.net/AMM.336-338.1170

3. V. Khmel, S. Zhao, IATSS Research 39(2), 138-145 (2016)

4. L. Kanapeckiene, A. Kaklauskas, E. Kazimieras Zavadskas, S. Raslanas, Expert Systems with Applications 38(11), 14196-14207 (2011)

5. S.V. Domnina, E.V. Savoskina, N.V. Shekhova, Procedia Engineering 153, 741-746 (2016)

6. V. Platon, S. Frone, A. Constantinescu, Economics and Finance 8, 204-210 (2014)

7. A. Borboni, M. Mor, R. Faglia, Journal of Dynamic Systems, Measurement and Control, Transactions of the ASME 138(11), 111003 (2016) DOI: 10.1115/1.4033831 